\title{
IMPLÍCITOS CODIFICADOS E A REPRESENTAÇÃO DA MULHER EM TEXTOS VERBO-VISUAIS
}

\author{
Beatriz dos Santos Feres \\ Universidade Federal Fluminense \\ https://orcid.org/0000-0001-5854-2898
}

\section{RESUMO:}

A partir do pressuposto de que a leitura competente demanda habilidades relacionadas às bases sociodiscursivas de todo texto, este artigo analisa implícitos codificados relacionados à representação da mulher em textos verbo-visuais. Define-se implícito codificado como um dado obtido na relação entre texto e contexto tanto a partir de regularidades comportamentais dos interagentes envolvidos nas trocas comunicativas, quanto das constantes caracterizadoras dessas trocas, ambas confirmadas por discursos de representação. Os implícitos codificados dizem respeito a dados externos, semiotizados por meio de índices e categorizados de acordo com as quatro condições de enunciação: de identidade, de finalidade, de propósito e de dispositivo (CHARAUDEAU, 2007). Diferentemente dos dados internos, linguageiros em sua essência, os externos orientam como dizer (e como compreender), sempre em relação ao contrato comunicativo que se estabelece em cada troca. $\mathrm{Na}$ extremidade da leitura, essas regularidades inscritas convencionalmente nos textos operam como constantes interpretativas altamente codificadas. A investigação partirá da hipótese de que os implícitos codificados em textos verbo-visuais de grande circulação social podem não só testemunhar um modo de ser e parecer mulher, mas também promover sua perpetuação, ou sua refutação. A análise estará fundamentada, prioritariamente, pela Teoria Semiolinguística de Análise de Discurso, não sem contar com a interface da Sociologia e da Psicologia Social. O corpus 
selecionado abriga textos dos gêneros meme, tirinha e conto ilustrado.

PALAVRAS-CHAVE: Implícito codificado. Representação da mulher. Verbo-visualidade.

\section{ENCODED IMPLICITS IN THE WOMAN REPRESENTATION IN VERB-VISUAL TEXTS}

\section{ABSTRACT:}

Based on the assumption that competent reading demands skills which are related to the socio-discursive bases of the whole text, this article analyzes encoded implicits related to the woman representation in verb-visual texts. The encoded implicit is defined here as a data obtained in the association between text and context, which emerge from the behavioral regularities of the interactants involved in the communicative exchanges, as well as from the characterizing constants of these exchanges, both confirmed by representational discourses. The encoded implicits refer to external data, semiotized through indexes and categorized according to the four conditions of enunciation: of identity, of finality, of purpose and of device (CHARAUDEAU, 2007). Contrasting to internal data, related to language in its essence, external data guides how to say (and how to understand), always in relation to the communicative contract that is established in each exchange. At the extremity of reading, these regularities conventionally inscribed in texts operate as highly encoded interpretative constants. The research will start from the hypothesis that the encoded implicit in verb-visual texts of great social circulation can not only evidence a way of being and looking like a woman, but also promote its perpetuation, or its refutation. The analysis will be mainly based on the Semiolinguistics Theory of Discourse Analysis, in interface with Sociology and Social Psychology. The corpus selected includes texts from the genres meme, comic strip and illustrated tale.

KEYWORDS: Encoded implicit. Woman's representation. Verb-visuality. 


\section{A mulher implícita}

Este artigo nasce da reverberação do paradoxo da doxa de Bourdieu (2017), isto é, do fato de ainda parecer haver pouca transgressão ou subversão contra a ordem de um mundo que considera aceitáveis, ou até mesmo naturais, condições de existência intoleráveis - como a da dominação masculina e do modo como é imposta e vivenciada, resultante da violência simbólica,

violência suave, insensível, invisível a suas próprias vítimas, que se exerce essencialmente pelas vias puramente simbólicas da comunicação e do conhecimento, ou, mais precisamente, do desconhecimento, do reconhecimento ou, em última análise, do sentimento. (BOURDIEU, 2017, p.1112)

Parte-se aqui da constatação de que a representação da mulher em textos verbo-visuais de farta circulação tem se tornado relevante fonte de problematização sobre a condição feminina, sobretudo em tempos de Lei Maria da Penha, de abordagem "politicamente correta" da mulher na publicidade (menos como objeto e mais como sujeito de suas vontades e ideias), ou ainda de forte reação à misoginia e ao confinamento feminino ao espaço exclusivamente doméstico, provando que o senso comum já demonstra mudança quanto ao modelo cristalizado de ser e parecer mulher "bela, recatada e do lar" - sobretudo, em textos de forte inclinação crítica.

Como um estudo de base semiolinguística, toma-se então como hipótese central a funcionalidade dos implícitos codificados mais ou menos ligados à representação da mulher, marcados indicialmente por signos verbais e imagéticos, em textos como memes, tirinhas e contos ilustrados, não só para testemunhar um modo de ser e parecer mulher, mas, sobretudo, para perpetuar ou refutar esse modo. Por implícito codificado entende-se o dado condicionado situacional ou discursivamente, inscrito em representações sociais, materializado por meio de signos de farta circulação.

Pretende-se identificar, nos textos, marcas verbais e imagéticas que, no conjunto que formam, acionam implícitos 
codificados direcionados à representação da mulher e vinculados, algumas vezes, à reconstrução de conceitos acerca de seu papel social. Para alcançar esse intento, também serão utilizadas interfaces com a Psicologia Social e a Sociologia.

\section{Constantes interpretativas: o implícito codificado}

Segundo Charaudeau (2008, p. 56), o sucesso do ato de linguagem se submete à coincidência das interpretações realizadas pelo sujeito interpretante (o interlocutor "real") e o sujeito destinatário (aquele para o qual o texto foi idealmente planejado pelo produtor), isto é, quanto maior ajuste entre a interpretação do interlocutor "real" e aquela imaginada pelo produtor para ele, mais chance de o ato lograr êxito. É preciso considerar, entretanto, que, muito mais do que no conhecimento das formas (linguísticas, imagéticas etc.) em si e de sua organização no texto, é no conhecimento discursivo-situacional partilhado entre os interagentes de uma troca que reside a chance desse êxito.

Em outras palavras, é preciso atentar que a capacidade inferencial não se alimenta exclusivamente de conhecimentos prévios dedicados ao repertório semântico do sujeito (quase sempre categorizado amplamente como enciclopédico), mas também de conhecimentos relacionados aos recorrentes modos de dizer e seus ambientes de uso, ou seja, aos conhecimentos relativos ao repertório discursivo-situacional, que contempla desde as estratégias de formalização do discurso, até as restrições impostas pelas circunstâncias de comunicação, ditadas pelo contrato comunicativo de cada troca, que envolve a identidade de cada interagente, seu "lugar de fala", o gênero discursivo utilizado, as representações sociais eleitas pelo grupo social de partilha e todas as implicações que dizem respeito a isso. Em outras palavras, a interpretação exitosa exige inferências em relação aos pontos de vista da enunciação, da visão perspectivada do mundo, discursivizada em cada troca comunicativa de acordo com códigos (vários) mais ou menos institucionalizados pelo uso. 
Neste trabalho, pretende-se focalizar o implícito codificado (tacitamente convencionalizado), isto é, o tipo de inferência que se realiza a partir de uma marca linguageira quando relacionada a um dado externo, ligado às circunstâncias de enunciação mais ou menos imediatas que envolvem a troca comunicativa. Nesse caso, a marca (palavra, expressão, imagem, aspecto plástico) aponta para o dado externo em função de sua recorrência naquele tipo de ambientação enunciativa. Trata-se de um tipo de implícito que está tão institucionalizado que parece natural, como se fosse parte do signo, mas, na verdade, está condicionado às circunstâncias de enunciação e seu aparato discursivo, sendo, em determinado ambiente, automático.

Charaudeau (Idem, p. 60) cita o emprego da palavra caipirinha por uma pessoa em um café, entendida pelo garçom como uma bebida, e não como uma pessoa do sexo feminino vinda da roça, ou da expressão "Praça da República", entendida pelo taxista como indicação do itinerário de viagem solicitado pelo passageiro. Em ambos os casos, a simples interpretação da expressão verbal depende da consideração das circunstâncias enunciativas, a partir do implícito codificado que "resulta dos estatutos do EUc e do TUi e da relação imaginada que os inter-define". Esses sujeitos, por estarem submetidos a um mesmo "terreno de conivência discursiva", sobredeterminados por um ritual sociolinguageiro, conseguem criar uma expectativa discursiva comum e dar um único sentido à marca linguageira.

Os dados externos são aqueles que, no campo de uma prática social determinada, se constituem pelas regularidades comportamentais dos indivíduos que aí efetuam trocas e pelas constantes que caracterizam essas trocas e permaneceram estáveis por um determinado período; além disso, essas constantes e essas regularidades são confirmadas por discursos de representação que lhes atribuem valores e determinam assim o quadro convencional no qual os atos de linguagem fazem sentido. Esses dados não são essencialmente linguageiros (o que os opõem aos dados internos), mas são semiotizados, pois correspondem a índices que, retirados do conjunto dos comportamentos sociais, apresentam uma convergência, configurando-se em constantes. (CHARAUDEAU, 2007, p. 68) 
Nesse sentido, pode-se afirmar (i) que o implícito codificado liga-se a um dado externo orbitante em torno do texto no universo das circunstâncias enunciativas e (ii) que sua inferência automática, acionada pela marca formal, dependerá do reconhecimento do ritual sociolinguageiro instituído nas interações e recorrente naquela ambientação. A análise do implícito codificado referenda "um projeto semiolinguístico que, mesmo permanecendo no contexto de uma problemática linguageira, permite tratar os aspectos sociológicos e psicológicos dos quais a linguagem é portadora", ao observar as estratégias de poder empregadas no seio de um grupo social como "resultado de um jogo de ser e de parecer entre o estatuto social dos sujeitos do circuito comunicativo (EUc/TUi) e o estatuto linguageiro dos sujeitos que a manifestação linguageira constrói (EUe/TUd)", como sugere Charaudeau (Idem, p. 62).

Um aspecto que não pode ser negligenciado nesta reflexão diz respeito ao deslocamento gradual da ambientação enunciativa, mais ou menos imediata à textualização. Nos exemplos oferecidos por Charaudeau, as circunstâncias de comunicação correspondem às situações de interação face a face e, claro, aos papéis sociais dos interagentes, submetendo a interpretação de expressões linguísticas aos rituais sociolinguageiros que envolvem as trocas (pedido ao garçom no café; indicação do itinerário ao motorista no táxi). A ambientação enunciativa, nesses casos, coloca imediatamente em evidência os interagentes e os papéis desempenhados nos rituais institucionalizados, que lhes legitimam - e proíbem - certos comportamentos e certas falas. Porém, em torno de um ato de linguagem postergado, monologal, sem o contato direto dos interagentes, fica em evidência um contexto mais "discursivo", ou mais "histórico-cultural", menos imediato. Nesses casos, os interagentes são "projetados" pelo enunciado. Em decorrência desse fato, é preciso considerar outros dados igualmente ligados às circunstâncias de comunicação - ainda não totalmente internos, linguageiros -, que também legitimam dizeres, como o gênero discursivo eleito para a comunicação e as representações sociais (em si) relacionadas ao universo referencial permitido em determinado contrato de comunicação.

Tanto quanto os dados externos dos exemplos citados por Charaudeau, o gênero discursivo, partilhado socialmente, impõe ambientação própria, regras de utilização, formas mais ou menos 
estáveis e temas, pressupondo constantes interpretativas e trabalhando como modelo coercitivo. Pode-se dizer que o gênero é um dado parcialmente discursivo, mas parcialmente situacional também, eleito pela circunstância comunicativa dada, igualmente influente no contrato comunicativo que se estabelece, conforme o ponto de vista de Bakhtin (2000, p. 311-312):

Quando escolhemos uma palavra, durante o processo de elaboração de um enunciado, nem sempre a tiramos, pelo contrário, do sistema da língua, da neutralidade lexicográfica. Costumamos tirá-la de outros enunciados, e, acima de tudo, de enunciados que são apresentados ao nosso pelo gênero, isto é, pelo tema, composição e estilo; selecionamos as palavras segundo as especificidades de um gênero. $\mathrm{O}$ gênero do discurso não é uma forma de língua, mas uma forma do enunciado que, como tal, recebe do gênero uma expressividade determinada, típica, própria do gênero dado. No gênero, a palavra comporta certa expressão típica. Os gêneros correspondem a circunstâncias e a temas típicos da comunicação verbal e, por conseguinte, a certos pontos de contato típicos entre as significações da palavra e a realidade concreta.

Considerando-se a "regularidade comportamental" suposta como resultado do gênero discursivo selecionado e o "discurso de representação" que o envolve, parece pertinente afirmar que, se os papéis assumidos pelos sujeitos do ato de linguagem constituem os dados externos prototípicos como legitimadores dos papéis assumidos por esses sujeitos, o gênero discursivo constitui um dado igualmente codificado, parcialmente exterior ao texto, mas que se materializa, discursivamente, em formas "mais ou menos estáveis" que habitam determinados universos referenciais. É um dado externo-interno que também deve ser visto como implícito codificado, institucionalizado, de domínio necessariamente partilhado entre os interagentes. Charaudeau o toma como o gênero situacional, emparelhado com o contrato de comunicação:

São, assim, os dados situacionais que induzem as regularidades discursivas, e estas as formas textuais. Estas últimas não estão ali se não como índices semiológicos que remetem a esses dados e permitem, assim, ao receptor, 
reconhecer o gênero-contrato com o qual ele trata. (CHARAUDEAU, 2004, p.33)

Outro aspecto que permite considerar o gênero discursivo como promotor do implícito codificado tem relação com as quatro categorias nas quais se agrupam os dados externos, de acordo com as condições de enunciação da produção linguageira, segundo Charaudeau (2007): condição de identidade, condição de finalidade, condição de propósito e condição de dispositivo. $\mathrm{Na}$ interação postergada, são categorias perceptíveis, sobretudo, a partir da origem genérica dos textos.

A condição de identidade dos parceiros engajados na troca é observada por meio dos traços identitários de natureza social e psicológica (idade, sexo, etnia etc.) que interferem no ato de comunicação, desde que estejam em uma relação de pertinência com $\mathrm{o}$ ato de linguagem. É a condição relacionada ao "direito à palavra" e às restrições impostas pelos papéis sociais assumidos pelos sujeitos interagentes: é o caso, por exemplo, do professor que, podendo conduzir atos de linguagem a partir do gênero aula, assume seu papel social hierarquicamente superior ao dos alunos e exige tarefas.

Já a condição de finalidade diz respeito ao objetivo de cada ato de linguagem e se define pela expectativa de sentido em que se baseia a troca. Refere-se à influência que o produtor deseja provocar sobre o interlocutor, por isso, realiza-se em termos de visadas, que podem ser combinadas entre si: a prescritiva (fazer fazer), a informativa (fazer saber), a incitativa (fazer crer) e a patêmica (fazer sentir). Como visto anteriormente, ao ler uma tirinha, já se tem, de antemão, a expectativa da crítica social como ingrediente da leitura por causa da visada característica do gênero, a de fazer crer.

O propósito é a condição referente a um domínio do saber, a uma espécie de macrotema admitido pelos parceiros envolvidos de acordo com um gênero discursivo específico. É "uma maneira de recortar o mundo em "universos de discurso tematizados" (Ibidem, p. 69), como no caso em que o passageiro, em um táxi, fala para indicar o itinerário e isso está pressuposto ao ato, mas não deve falar sobre suas intimidades, como se estivesse em um divã.

Por fim, a condição de dispositivo impõe regras para ao ato de comunicação em função da natureza da situação de comunicação e das condições materiais em que ele ocorre, construindo o quadro 
topológico da troca no "entre-lugar" externo-interno ocupado, sobretudo, pelo gênero discursivo. Em Discurso político, Charaudeau (2006, p. 53-54) trata o dispositivo como um macrodispositivo conceitual, que "estrutura a situação na qual se desenvolvem as trocas linguageiras ao organizá-las de acordo com os lugares ocupados pelos parceiros da troca, a natureza de sua identidade, as relações que se instauram entre eles em função de certa finalidade" e em microdispostivos materiais, que correspondem não só aos canais de comunicação, ou às condições efetivamente materiais da troca, mas também aos gêneros. Observa-se a atuação do dispositivo, por exemplo, na publicidade, como gênero, veiculada pelo rádio ou pela televisão, cujos recursos linguageiros são selecionados a partir de suas viabilidades técnicas.

Como é possível concluir, os dados externos se concretizam nos dados internos, isto é, nos dados propriamente discursivos: nos comportamentos efetivos dos parceiros da troca, em sua maneira de falar, nas formas (verbais, icônicas etc.) que devem empregar nos espaços da locução, da "tomada da palavra" (espaço da relação entre o sujeito falante e o interlocutor) e o da tematização, do domínio do saber, do tema.

Contrato de comunicação e projeto de fala se completam, trazendo, um, seu quadro de restrições situacionais e discursivas, outro, desdobrando-se num espaço de estratégias, o que faz com que todo ato de linguagem seja um ato de liberdade, sem deixar de ser uma liberdade vigiada. (CHARAUDEAU, 2007, p. 71)

Ressalta-se novamente aqui, para além do caráter praxeológico dos dados externos, seu caráter axiológico, responsável pela avaliação institucionalizada de seu emprego nas trocas comunicativas. Em outras palavras, não se mostra suficiente reconhecer circunstâncias da enunciação e esquemas de ação dali decorrentes; é igualmente relevante reconhecer os lugares sociais de posicionamento dos sujeitos interagentes e os sistemas de valores que envolvem suas escolhas discursivas. Nisso consiste a observação dos imaginários sociodiscursivos e das representações sociais por meio dos quais é possível qualificar as identidades postas em cena na troca, seu comportamento, seus modos de dizer. 
O caráter axiológico que recobre os dados externos indica um deslocamento gradual do contexto mais imediato da troca em direção ao contexto mais mediato, ao conjunto do mundo social, isto é, às instituições referendadas pelas comunidades de fala, às práticas culturais, à história. Isso significa que o implícito codificado, como dado orbital ligado à situação de comunicação e à validação dos papéis sociais, dos comportamentos dos interagentes e de seu modo de dizer, também consiste naquilo que tudo isso representa para o grupo social, em um julgamento intrínseco e constante.

\section{Implícitos codificados na composição verbo-visual de textos}

Parece relevante explicar inicialmente que, neste trabalho, destacam-se alguns textos cuja composição formal e/ou cuja significação esteja afetada, em graus variados, pela influência recíproca entre palavra e imagem. Soma-se a isso a capacidade avaliativa própria do sentimento de identidade e de pertença dos grupos sociais, que enxerga o material simbólico por uma perspectiva comum e apreende seus valores e diferenças.

O primeiro caso apresentado está configurado em um meme, cuja integração entre palavra e imagem pode ser considerada bastante elevada. Meme é um gênero discursivo de recente partilhamento, próprio das redes sociais, que tem como características básicas, além da verbo-visualidade formal (no caso dos memes estáticos), o caráter crítico-humorístico e, principalmente, a replicabilidade. Quase sempre os memes surgem de uma imagem ou fala bastante conhecida e ganham rapidamente novas versões, que mantêm algum elemento - verbal ou visual - do meme-fonte. É um gênero marcadamente relacionado à crítica social, como o são as charges, cartuns e tirinhas. Nele se observa uma condensação intensa de sentidos, geralmente na apresentação de uma única cena de natureza narrativa, em que personagens agem e se expressam, emprestando sua identidade para a enunciação. 
Figura 1 - Meme sobre feminista ${ }^{1}$

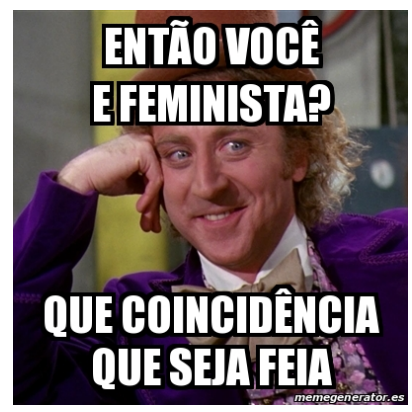

O meme em questão (Figura 1) apresenta como protagonista o personagem do conhecido filme "A fantástica fábrica de chocolate", vivido por Gene Wilder na versão de 1971 (Warner Bros), que empresta seu sarcasmo ao comentário: "Então você é feminista? Que coincidência que seja feia".

As expectativas acerca do sarcasmo e da crítica social são criadas a partir dos implícitos codificados indicados pela expressão facial e gestual da personagem no intertexto, por seu caráter e pelas características do dispositivo: o gênero discursivo meme, circulante nas redes digitais. Esses implícitos estão baseados em dados externos, oriundos de um contexto menos imediato, mas incorporados pelo sujeito-comunicante e, portanto, atuantes na enunciação, na elaboração do sujeito enunciador, cuja identidade parece se revestir de legitimidade para falar de forma antipática a propósito do "feminismo", constitutivo da representação da mulher na atualidade, com a finalidade de avaliá-lo negativamente e angariar a concordância (ou a repugnância) do interlocutor. Aquilo que afirma, indiretamente - as feministas são feias e, por isso, são

\footnotetext{
${ }^{1}$ Disponível em https://www.memegenerator.es/meme/28078204. Acesso em 09 set 2019.
} 
feministas - traz, implicitamente, uma avaliação preconceituosa acerca das feministas e do feminismo, mas, provavelmente, revela algo que ecoa em boa parte da sociedade.

Para as feministas e seus apoiadores, porém, o sarcasmo implícito e codificado corrobora a ignorância por parte do sujeito comunicante e a falta de respeito subentendida na afirmação. Tratase de uma dupla interpretação possível em decorrência da alteração do destinatário, ou da não adesão do sujeito interpretante ao destinatário planejado na textualização, ou seja, alguém que concordaria com o ponto de vista enunciado.

$\mathrm{Na}$ contramão do ponto de vista apresentado nesse meme, circulam textos que substituem os estereótipos negativos de que se reveste o feminismo ou a mulher pela proposta de reflexão acerca da condição feminina e da afirmação do movimento feminista como atitude emancipadora (às vezes mais, às vezes menos radical). Como exemplo, as charges e tirinhas de Bruno Drummond e de Maitena, dentre tantas outras, e a consagrada Mafalda, de Quino.

Em uma das tirinhas da $\mathrm{Mafalda}^{2}$, por exemplo, a menina questionadora se aproxima entusiasmada da mãe e fala: "Mamãe! Que futuro você vê nesse movimento pela libertação da mulher? Não, nada, esquece" (Tradução livre). O balão com a fala se estende pelos quatro quadros que compõem a tira. A grafia das palavras, inicialmente em letras enormes e risco forte, diminui aos poucos, terminando bem pequenas, indicando, plasticamente (por outro implícito codificado), o entusiasmo que se esvai junto com o tom de voz da menina, que vê uma tábua com uma pilha de roupas para passar, a casa desarrumada para limpeza e a mãe agachada esfregando o chão, cumprindo seu "papel de mulher".

Outro recurso discursivo desse conjunto de gêneros verbovisuais é a repetição da imagem da personagem em vários quadros e em posições e gestos diferentes, codificando uma sequência de ações - mais do que apresentando a simples repetição da personagem - e, com isso, fazendo avançar a narrativa. Mas os scripts vividos pelas personagens no circuito interno do texto - a pergunta da criança curiosa e o trabalho doméstico que a mãe de família realiza -

${ }^{2}$ Disponível em https://www.pinterest.pt/pin/362680576224936818/ Acesso em 09 set 2019. 
atualizam implícitos codificados ligados aos papéis sociais que as personagens assumem e fazem parte do repertório partilhado pelo grupo social que produz e consome esse tipo de texto.

A projeção provocada pela narrativa permite o leitor se colocar na cena, ajustando as personagens às suas experiências de vida e, com isso, salientando a constatável continuidade da condição feminina. A projeção, enfim, está baseada em implícitos codificados próprios do dispositivo, que colocam a Mafalda como enunciadora do sujeito-comunicante Quino, alguém que problematiza o movimento de liberação feminina, com a legitimidade garantida pela identidade de cartunista e pelo gênero tirinha, justamente por sua finalidade de fazer questionar, fazer refletir, fazer-crer, persuadir. $\mathrm{Na}$ extremidade da interpretação, o leitor cria expectativas em função desses implícitos, tais como o pressuposto da crítica, do posicionamento do cartunista, da adesão que deve aceitar como sujeito-interpretante, assumindo ou não o posicionamento acerca do tema proposto.

Também em contos ilustrados para crianças, o implícito codificado relacionado à representação da mulher é acionado constantemente, servindo de "guia ideológico" das novas gerações para perpetuar valores "tradicionais", ou evidenciá-los para refutálos. Segundo Colomer (2017, p. 62), por causa da função socializadora observada nos livros destinados à infância e à juventude, "não há melhor documento que a literatura infantil para saber a forma como a sociedade deseja ver-se a si mesma".

Em Super (ALPHEN, 2017, p. 1-14), o menino protagonista relata o cotidiano de seu pai e de sua mãe:

Todos os dias, papai sai bem cedinho para trabalhar. Mamãe também. Papai voando! E Mamãe me leva para a escola antes de ir para o trabalho. É sempre assim. Papai sai voando pela manhã. E sempre volta à noitinha. E Mamãe também. Algumas noites, Papai dá uma paradinha para ver meu programa predileto. Enquanto mamãe faz a pipoca! Algumas noites, Papai volta do trabalho acompanhado de seus supercolegas... ...Até mesmo quando Mamãe está supercansada.

A parcela verbal é disposta lentamente, distribuída ao longo das páginas, enquanto ilustrações preenchem a maior parte de cada 
folha dupla, mostrando, inicialmente, um pai vestido com máscara e capa, como super-herói, que sai voando para o trabalho, e uma mãe vestida "prototipicamente", ou seja, com um avental. Essa percepção do menino em relação aos pais se altera ao longo do conto, pois o pai, surpreendentemente, passa a buscá-lo na escola no lugar da mãe, além de assumir tarefas domésticas, já sem a roupa de super-herói, à medida que a mãe passa a ficar mais tempo fora de casa, no trabalho, até que o menino percebe que a mãe também é "super".

Em textos verbo-visuais, trabalha-se com um implícito codificado de partida, calcado nos gêneros discursivos que assim se formatam: a expectativa de convergência semântica entre parcelas sígnicas verbal e visual mais ou menos complementares. Em Super (Idem, 2017), um narrador em primeira pessoa, exposto na parte verbal, fala de seu cotidiano com os pais. Em um movimento de correferenciação, a imagem do menino é automaticamente reconhecida como a do narrador e a dos adultos, como a de seus pais - justamente por causa dos implícitos codificados relacionados a esses papéis sociais e os modos de agir atrelados a eles. A relação familiar entre as personagens também é pressuposta em virtude de um implícito codificado relacionado à família como instituição social bastante cristalizada, geralmente composta por uma mãe, um pai e, ao menos, um filho.

Entretanto, no conto, os objetos pai e mãe são recategorizados pela visualidade, quebrando a expectativa quanto à avaliação do papel do homem e da mulher: inicia-se o texto com uma representação paterna revestida de indumentária de super-herói, carregada metaforicamente de uma avaliação bastante positiva quanto ao trabalho exercido pelo homem na esfera pública (a mãe também trabalhava fora, além de executar as tarefas domésticas, mas, no começo do conto, não estava vestida de super-heroína). Essa avaliação positiva direcionada ao pai só migra para a caracterização da mãe como "super" quando ela assume a função de provedora, antes atribuída apenas ao pai. O pai, por sua vez, perde o caráter "super" justamente à medida que passa a ficar em casa e a assumir as tarefas domésticas. Novamente, implícitos codificados em relação à atuação do homem e da mulher em ambiente familiar são utilizados como base para a interpretação dessas caracterizações.

Em outras palavras, o conto parece pretender tematizar a capacidade feminina de assumir atividades tradicionalmente 
masculinas e colocar o homem como aquele que também pode assumir tarefas domésticas, tradicionalmente femininas. Entretanto, perpetua-se a diferenciação qualitativa entre a esfera pública e a privada, entre a valorização do trabalho "fora de casa", próprio ainda do homem, "coisa de super-herói", e aquele doméstico, desimportante e sem projeção social, ainda quase exclusivo da mulher. A superioridade heroica atribuída no conto à mulher que "trabalha fora", "marcada", "assinalada" por ser considerada excepcional, permanece atrelada a posições sociais ainda bastante estigmatizadas - e é na metáfora visual que o preconceito ganha expressão.

A representação da mulher como heroína quando igualada ao homem no que tange ao trabalho "fora de casa" corrobora a ideia de que a conquista da esfera pública por parte dela está entre os mais relevantes fatores de mudança da condição feminina, conforme Bourdieu (2017, p.124-125):

A maior mudança está, sem dúvida, no fato de que a dominação masculina não se impõe mais com a evidência de algo que é indiscutível. (...) O questionamento das evidências caminha pari passu com as profundas transformações por que passou a condição feminina, sobretudo nas categorias sociais mais favorecidas: é o caso, por exemplo, do aumento do acesso ao ensino secundário e superior, ao trabalho assalariado e, com isso, à esfera pública; é também o distanciamento em relação às tarefas domésticas e às funções de reprodução (...); é, sobretudo, o adiamento da idade do casamento e da procriação, a abreviação da interrupção da atividade profissional por ocasião do nascimento de um filho, e também a elevação dos porcentuais de divórcio e queda dos percentuais de casamento.

Já quanto ao distanciamento do trabalho doméstico, Bourdieu (2017) também explica, em letras pequenas de uma nota de rodapé, tratar-se de um fator que, apesar de nada ter de negligenciável, ocorre através da agregação de ações individuais nas unidades domésticas e no mundo do trabalho. Esse comentário discreto relacionado a ações individuais que, claro, não estão protocoladas como causa feminista, parece omitir, como também ocorre no conto, o valor negativo e o peso da responsabilidade das enfadonhas tarefas 
domésticas atribuídas à mulher e ao caráter feminino, exclusivamente.

Se a linguagem permite trazer para a superfície do texto os implícitos que circulam na sociedade em virtude de uma codificação automática, sendo compreendidos, muitas vezes, como "verdades" ou "certezas naturais", é ela também que permite sua identificação e, a partir disso, sua problematização. O que se subentende com essa narrativa é que concordar com o empoderamento feminino, mostrando a capacidade que a mulher apresenta para tarefas consideradas do universo masculino, é um passo em direção à valorização da mulher, ainda que continuemos a entender como "óbvia" e "natural" a ideia de que o trabalho doméstico não deva ser considerado próprio de um super-herói.

A não problematização da esfera privada é "unânime" e consensual, provando, mais uma vez, uma "certeza" inconsciente que garante a valorização da esfera pública e referenda a reação e a avaliação do protagonista-menino (e dos leitores), mostrando como pensar e como agir de acordo com essa "certeza". Nossa percepção se automatiza, e todo o processo de comunicação fica afetado por um determinado modo de reagir diante dessa realidade, seja na maneira de nos comportarmos como homens e mulheres graças aos nossos traços identitários, seja na finalidade dos papéis que julgamos possíveis para cada indivíduo, para cada gênero discursivo, para cada dispositivo.

Veicular essas ideias por meio de um conto ilustrado para crianças é uma maneira de, mais uma vez, repetir certos valores e modos de dizer, mas também de questionar outros. Tudo isso é obra do implícito codificado inferido nos modos de agir, falar e compreender de todo indivíduo colocado em relação com outros.

\section{Ser e parecer mulher por meio das constantes interpretativas}

Retomando o propósito deste trabalho - a função dos implícitos codificados em textos verbo-visuais nos quais se observa a representação da mulher - e apesar dos limites das análises aqui propostas, parece ter sido possível verificar como membros de um 
mesmo universo social estão condicionados a reagir de uma única maneira em suas trocas comunicativas em função dos saberes que os identificam como grupo. As constantes interpretativas, em sua recorrência, permitem uma intersubjetividade facilitada pelo reconhecimento automático das formas, das situações de comunicação, dos recursos discursivos. Como parte dessas constantes, os implícitos codificados atuam tanto no nível situacional de construção dos sentidos, como no nível discursivo, e são indicados por algum elemento formal.

Nas trocas comunicativas, a situação que as envolve determina como devem agir os interagentes, tanto na esfera da produção, quanto na da interpretação. Os papéis dos sujeitos envolvidos, seu modo de agir e usar a linguagem, o comportamento esperado naquelas circunstâncias e o que esperar daquele ato de linguagem seguem regras de atuação e de entendimento, tanto na troca face a face, quanto na postergada, registrada pela escrita e/ou pela imagem, como nos casos em tela. Cabe nesse item a observação dos gêneros discursivos (ou situacionais, segundo Charaudeau, 2004) e seus implícitos codificados próprios, que modelam as maneiras de dizer e de interpretar, criando expectativas e direcionando o entendimento.

Para além de organizar as formas e as regras de comunicação, os implícitos codificados também se vinculam aos propósitos das trocas, igualmente condicionados por dados externos ligados às circunstâncias enunciativas, mas, não menos importante, muitas vezes direcionados pelo imaginário sociodiscursivo naquilo que diz respeito às crenças e valores partilhados. Quem interpreta, portanto, sabe que um texto daquele gênero situacional pode ou não ser usado por indivíduos com tal ou qual atuação social, para tratar de um tipo de tema ou assunto, com uma intencionalidade esperada para esse tipo de troca e lançando mão de recursos expressivos de variada ordem também condicionados pelos dados externos.

Dessa maneira, para a compreensão do processo de construção de sentidos, parece ser tão importante saber que um meme, ou uma tirinha carrega a expectativa da criticidade, ou que uma narrativa ilustrada para crianças tem caráter formativo, quanto saber que a representação da mulher em nossa sociedade ainda se mostra bem marcada pela subalternidade e pela pouca liberdade. Esses são todos dados implícitos, quase sempre inconscientes, 
acionados automaticamente, codificados pelo e para o bom funcionamento da linguagem, orientando nossa maneira de compreender o mundo. Os implícitos codificados costuram nosso entendimento a partir de práticas interacionais que se perpetuam e modelam atitudes e regras de socialização.

Entretanto, se gêneros discursivos são atualizados de acordo com o desenvolvimento tecnológico, por exemplo, e com as necessidades dos indivíduos, o senso comum que comanda os implícitos codificados fundados em saberes de crença também são passíveis de mudança. Como defende Moscovici (2015), a sociedade "pensa", isto é, a mente humana não é uma "caixa-preta" dentro de uma "caixa-preta maior", onde se armazenam informações, palavras e gestos transformados em gestos, juízos e opiniões, nem os grupos e as pessoas estão totalmente sob o controle de uma ideologia dominante, como se não produzissem nada original, apenas reproduzindo e sendo reproduzidos. Assim, é possível subverter "certezas", numa atitude de resistência, afinal, "existe uma necessidade contínua de re-construir o 'senso comum' ou a forma de compreensão que cria o substrato das imagens e sentidos, sem a qual nenhuma coletividade pode operar" (MOSCOVICI, 2011, p. 48).

Ao se materializarem em tramas reconhecíveis a partir dos elementos do universo de partilha dos indivíduos, acionando a memória e as categorias ali armazenadas, as ideias novas, "subversivas" quanto ao senso comum, levam-nos ao conhecimento "assistido" de uma nova representação, ou de uma nova perspectiva, que, aos poucos, a partir da interação entre os indivíduos, pode ser aceita como um novo senso comum, mais afeito à tolerância humana. A representação da mulher é, hoje, portanto, ainda a mesma e diferente, justamente pelo movimento de resistência que precisa se pautar naquilo que é conhecido a fim de propor um novo olhar a partir das evidências que gêneros como memes, tirinhas e contos ilustrados, por exemplo, colocam à mostra.

\section{REFERÊNCIAS}

ALPHEN, Jean-Claude. Super. São Paulo: Pulo do Gato, 2017.

BAKHTIN, Mikhail. Estética da criação verbal. 3.ed. São Paulo: Martins Fontes, 2000. 
BOURDIEU, Pierre. A dominação masculina: a condição feminina e a violência simbólica. Trad. Maria Helena Kühner. 5.ed. Rio de Janeiro: Bestbolso, 2017.

CHARAUDEAU, Patrick. Linguagem e discurso. São Paulo: Contexto, 2008.

CHARAUDEAU, Patrick. Discurso das mídias. São Paulo: Contexto, 2007.

CHARAUDEAU, Patrick. Discurso político. São Paulo: Contexto, 2006.

CHARAUDEAU, Patrick. Visadas discursivas, gêneros situacionais e construção textual. In: MACHADO, Ida Lúcia; MELLO, Renato. Gêneros: reflexões em análise do discurso. Belo Horizonte, MG: Nad/Fale-UFMG, 2004, p.13-41.

MOSCOVICI, Serge. As representações sociais: investigações em Psicologia Social. 11.ed. Petrópolis - RJ: Editora Vozes, 2015.

Recebimento em: 27/10/2019 Aceito em: 09/03/2020 